\title{
METODE COKRIGING UNTUK MENGESTIMASI KANDUNGAN AIR DI KOTA PONTIANAK
}

\author{
Marwalida Rachmadiar, Naomi N. Debataraja, Hendra Perdana
}

\begin{abstract}
INTISARI
Air merupakan kebutuhan yang sangat penting bagi manusia. Kualitas air dapat ditentukan dengan melihat standar baku mutu kesehatan lingkungan untuk keperluan higiene sanitasi. Salah satu indikator fisik penentu kualitas air adalah Total Dissolved Solid (TDS). TDS adalah indikator yang menunjukkan kandungan padatan terlarut dalam air yang termasuk didalamnya senyawa-senyawa organik dan anorganik, mineral dan garam-garamnya. Salah satu senyawa kimia yang dapat membantu memperkirakan kandungan TDS adalah kesadahan. Penelitian ini bertujuan untuk mengestimasi kandungan TDS dengan metode cokriging. Metode cokriging adalah metode estimasi yang meminimalkan kesalahan estimasi dengan memanfaatkan korelasi silang antara beberapa variabel. Kesadahan menjadi variabel tambahan dalam membantu mengestimasi TDS pada lokasi baru yang ditentukan. Model semivariogram teoritis TDS, kesadahan dan cross semivariogram yang digunakan adalah model exponential. Berdasarkan hasil analisis dan pembahasan yang telah dilakukan diperoleh estimasi TDS pada sembilan titik lokasi baru yang ditentukan dan airnya digunakan untuk kebutuhan higiene sanitasi masyarakat di sekitar lokasi tersebut. Hasil estimasi TDS terbesar di Parit Tokaya yaitu sebesar 76,3 $\mathrm{mg} / \mathrm{l}$ dan hasil estimasi terkecil di parit sekitar Jalan Tani yaitu sebesar 17,2 mg/l.
\end{abstract}

Kata Kunci: variogram, higiene sanitasi, kualitas air, cokriging

\section{PENDAHULUAN}

Air merupakan kebutuhan hidup manusia khususnya untuk keperluan higiene sanitasi. Dalam Peraturan Menteri Kesehatan Republik Indonesia Nomor 32 Tahun 2017, air untuk keperluan higiene sanitasi tersebut digunakan untuk pemeliharaan kebersihan perorangan seperti mandi dan sikat gigi, serta untuk keperluan cuci bahan pangan, peralatan makan, dan pakaian. Selain itu, air untuk keperluan higiene sanitasi dapat digunakan sebagai air baku untuk minum. Kualitas air dapat ditentukan dengan melihat standar baku mutu kesehatan lingkungan untuk keperluan higiene sanitasi. Standar baku mutu kesehatan lingkungan media air untuk keperluan higiene sanitasi menurut Peraturan Menteri Kesehatan Republik Indonesia Nomor 32 Tahun 2017 meliputi parameter fisik, biologi, dan kimia. Salah satu parameter fisik penentu kualitas air adalah Total Dissolved Solid (TDS). Senyawa-senyawa organik dan anorganik yang larut air, mineral dan garam-garamnya termasuk didalam TDS. Salah satu senyawa kimia yang dapat membantu memperkirakan kandungan TDS di dalam air adalah kesadahan. Kesadahan merupakan suatu keadaan dengan kandungan kapur yang berlebihan dalam air.

Kadar TDS dapat diketahui dengan mengambil sampel kandungan TDS di suatu lokasi dan dianalisis di laboratorium. Namun karena keterbatasan dana penelitian, lokasi yang dijadikan sampel tidak bisa menyeluruh sehingga ada lokasi yang tidak dijadikan sampel. Kadar TDS di lokasi yang tidak tersampel dapat diestimasi dengan menggunakan kadar TDS dan kesadahan di lokasi terdekat. Metode yang dapat digunakan adalah kriging, universal kriging, robust kriging, dan cokriging. Estimasi menggunakan dua variabel menggunakan metode cokriging. Metode cokriging adalah metode estimasi yang meminimalkan varians kesalahan estimasi dengan memanfaatkan korelasi silang antara beberapa variabel [1].

Tujuan dari penelitian ini adalah mengestimasi kandungan TDS dengan metode cokriging. Penelitian ini dapat membantu memberi gambaran kualitas air di Kota Pontianak. Penelitian ini dibatasi pada data penelitian mengenai kandungan TDS dan kesadahan pada air di Kota Pontianak 
yang diambil pada tahun 2018. Pengambilan data dilakukan dengan menggunakan stratified random sampling dan didapatlah 41 lokasi yang memiliki koordinat absis dan ordinat di zona UTM 49S dan kemudian dijadikan sampel. Variabel yang diestimasi dalam penelitian ini adalah variabel TDS, sedangkan variabel yang membantu proses estimasi adalah kesadahan $\left(\mathrm{CaCo}_{3}\right)$. Pengerjaan dalam penelitian ini menggunakan bantuan software Microsoft Excel dan $R$.

Tahapan estimasi dengan cokriging yang pertama kali dilakukan adalah uji korelasi antara TDS dan kesadahan. Langkah berikutnya adalah melakukan analisis semivariogram eksperimental pada TDS, kesadahan maupun cross semivariogram antara TDS dan kesadahan. Langkah berikutnya yaitu melakukan analisis lanjutan dengan mencari nilai semivariogram teoritis. Semivariogram teoritis yang digunakan adalah model spherical, exponential dan gaussian. Setelah nilai semivariogram teoritis didapatkan, selanjutnya mencari model terbaik diantara tiga model semivariogram teoritis dengan mencari nilai semivariogram teoritis yang paling dekat dengan semivariogram eksperimental dengan membandingkan nilai Mean Square Error (MSE). Langkah terakhir adalah melakukan estimasi cokriging terhadap TDS di lokasi baru yang telah ditentukan.

\section{VARIOGRAM}

Variogram adalah metode analisis keragaman data spasial yang didasarkan pada pengukuran jarak [1]. Variogram didefinisikan sebagai:

$$
2 \gamma(h)=E[(Z(u+h)-Z(u))]^{2}
$$

Semivariogram pada jarak $h$ adalah setengah dari variogram dengan simbol $\gamma(h)$. Semivariogram pada jarak $h$ didefinisikan sebagai berikut [1]:

$$
\gamma(h)=\frac{1}{2} E[(Z(u+h)-Z(u))]^{2}
$$

Adapun unsur-unsur yang terkandung dalam semivariogram [2]:

1. Sill

Sill adalah saat dimana nilai semivariogram cenderung mencapai nilai yang stabil. Sill dinotasikan dengan $c$.

2. Range

Range merupakan jarak pada saat semivariogram mencapai sill. Range dinotasikan dengan $a$.

3. Nugget Effect

Pada dasarnya nilai semivariogram selalu bernilai 0 pada titik $h=0$. Akan tetapi, jika nilai semivariogram pada $h=0$ tidak bernilai 0 , maka dapat dikatakan bahwa semivariogram mempunyai nugget effect.

Semivariogram eksperimental adalah semivariogram yang diperoleh dari hasil pengukuran data spasial yang ada di lapangan. Semivariogram eksperimental dirumuskan sebagai berikut [2]:

$$
\gamma(h)=\frac{1}{2 N(h)} \sum_{i=1}^{N(h)}\left[Z\left(u_{i}+h\right)-Z\left(u_{i}\right)\right]^{2}
$$

dengan $h$ adalah jarak, $N(h)$ adalah banyaknya pasangan titik yang mempunyai jarak $h, Z\left(u_{i}+\right.$ $h$ ) merupakan nilai pengamatan di titik $u_{i}+h$, dan $Z\left(u_{i}\right)$ merupakan nilai pengamatan di titik $u_{i}$. Analisis lebih lanjut yang dilakukan yaitu membandingkan nilai MSE antar model pada semivariogram teoritis. Hal ini bertujuan untuk menentukan model terbaik yang kemudian digunakan untuk perhitungan hasil estimasi. Ada beberapa model semivariogram teoritis yang diketahui, yaitu [2]:

\section{a. Exponential Model}

Bentuk semivariogram ini dirumuskan sebagai berikut: 


$$
\gamma(h)=c\left[1-\exp \left(-\frac{h}{a}\right)\right]
$$

b. Spherical Model

Bentuk semivariogram ini dirumuskan sebagai berikut:

$$
\gamma(h)=\left\{\begin{array}{c}
c\left[\frac{3}{2} \frac{h}{a}-\frac{1}{2}\left(\frac{h}{a}\right)^{3}\right], \text { jika } h \leq a \\
c, \text { jika } h>a
\end{array}\right.
$$

c. Gaussian Model

Bentuk semivariogram ini dirumuskan sebagai berikut:

$$
\gamma(h)=c\left[1-\exp \left(-\left(\frac{h}{a}\right)^{2}\right)\right]
$$

\section{COKRIGING}

Cokriging adalah metode estimasi yang meminimumkan varians kesalahan estimasi dengan menggunakan korelasi silang antara beberapa variabel [3]. Selain itu, jika seluruh variabel yang diukur pada seluruh lokasi sampel tersebut berkorelasi, maka cokriging lebih tepat digunakan daripada kriging [1]. Cokriging menggunakan variabel tambahan atau sekunder yang disebut juga sebagai kovariat, selain dari variabel utama atau primer. Variabel tambahan tersebut digunakan untuk mengestimasi variabel utama pada lokasi yang tidak disampel. Estimasi cokriging merupakan kombinasi linier dari data variabel primer dan variabel sekunder yang dinyatakan sebagai berikut [3]:

$$
\hat{u}_{0}=\sum_{i=1}^{n} a_{i} u_{i}+\sum_{j=1}^{m} b_{j} v_{j}
$$

di mana $\hat{u}_{0}$ adalah estimasi dari $U$ pada lokasi $0 ; u_{1}, u_{2}, \ldots, u_{n}$ adalah data variabel utama pada $n$ lokasi terdekat; $v_{1}, v_{2}, \ldots, v_{m}$ adalah data variabel sekunder pada $m$ lokasi terdekat, $a_{1}, a_{2}, \ldots, a_{n}$ dan $b_{1}, b_{2}, \ldots, b_{m}$ adalah pembobot cokriging yang harus ditentukan.

\section{ESTIMASI TOTAL DISSOLVED SOLID (TDS)}

Data yang digunakan pada penelitian ini adalah data penelitian mengenai kandungan TDS dan kesadahan dalam air di permukiman Kota Pontianak yang diambil pada tahun 2018. Pengambilan lokasi sampel dilakukan dengan metode stratified random sampling. Populasi dikelompokan menjadi subpopulasi dengan memperhatikan strata (tingkatan) di dalam populasi. Subpopulasi dibentuk berdasarkan kriteria daerah yang dialiri oleh anak sungai yang sama merupakan daerah yang homogen. Sampel air yang diambil adalah sampel air permukaan yang mengalir. Kemudian dari masing-masing subpopulasi diambil titik-titik lokasi yang menjadi sampel [4]. Terpilihlah 41 titik lokasi yang dijadikan sampel. Penelitian ini menggunakan data titik lokasi yang berupa koordinat garis bujur dan lintang di zona 49 South yang dikonversi ke dalam koordinat Universal Transverse Mercator (UTM) menjadi easting yaitu titik absis $(x)$ dan northing yaitu titik ordinat $(y)$. Titik lokasi sampel dapat dilihat pada Gambar 1. 


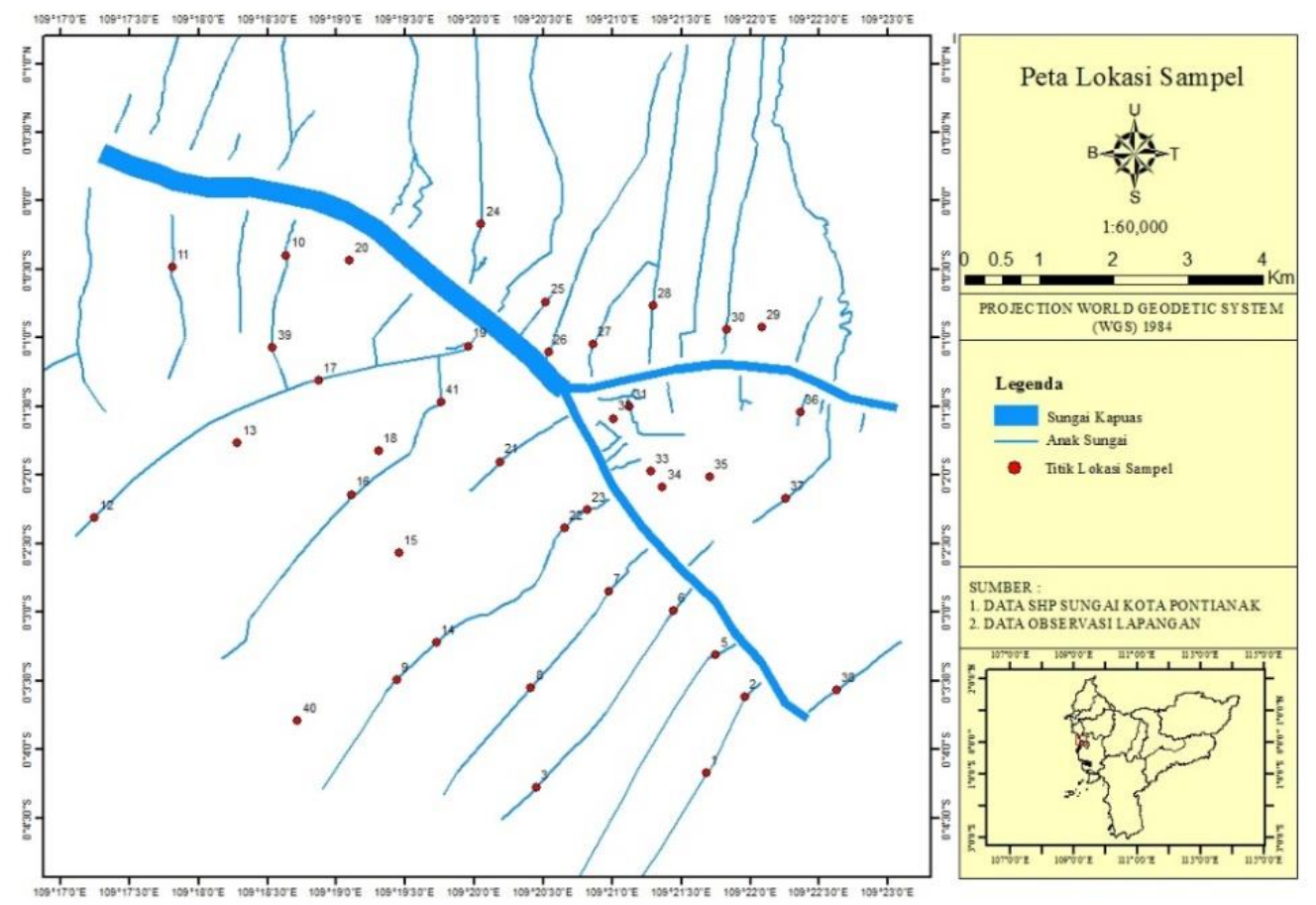

Gambar 1. Peta Titik Lokasi Sampel

Dalam penelitian ini TDS berperan sebagai variabel utama dan kesadahan sebagai variabel tambahan. Variabel utama dan variabel tambahan menggunakan satuan $\mathrm{mg} / \mathrm{l}$. Ringkasan data variabel yang digunakan dapat dilihat dalam Tabel 1.

Tabel 1 Statistik Deskriptif Data Kualitas Air di Pontianak

\begin{tabular}{lrr}
\hline & Min & Max \\
\hline Kesadahan (mg/l) & 8,0 & 68,0 \\
TDS (mg/l) & 17,2 & 156,3 \\
\hline
\end{tabular}

Dalam Tabel 1 dilihat bahwa nilai minimal dari data kesadahan adalah $8 \mathrm{mg} / \mathrm{l}$ dan nilai maksimalnya adalah $68 \mathrm{mg} / \mathrm{l}$. Nilai minimal dari data TDS adalah 17,2 mg/l dan nilai maksimalnya adalah $156,3 \mathrm{mg} / \mathrm{l}$. Variabel primer dan variabel sekunder harus memiliki korelasi untuk melakukan estimasi cokriging. Korelasi variabel TDS dan variabel kesadahan adalah sebesar 66\% dan bernilai positif dengan tingkat korelasi masuk dalam kategori cukup kuat. Semakin besar kandungan kesadahan maka semakin besar juga kandungan TDS di dalam air.

\section{Semivariogram Total Dissolved Solid}

Pada Tabel 2 disajikan nilai semivariogram eksperimental dari TDS yang dibantu dengan menggunakan software $R$.

Tabel 2 Nilai Semivariogram Eksperimental TDS

\begin{tabular}{rrrr}
\hline Kelas Jarak & Pasangan $(N(h))$ & $\operatorname{Jarak}(h)$ & Semivariogram $(\gamma(h))$ \\
\hline $0-1667$ & 87 & 1214,6010 & 692,4462 \\
$1667-3334$ & 227 & 2552,4620 & 1048,2873 \\
$3334-5001$ & 237 & 4145,9130 & 1336,7207 \\
$5001-6668$ & 181 & 5781,6890 & 2008,7192 \\
$6668-8335$ & 68 & 7399,2370 & 2554,4394 \\
$8335-10002$ & 18 & 8998,3400 & 1880,2742 \\
$10002-11669$ & 2 & 10414,0170 & 509,6500 \\
\hline
\end{tabular}


Jumlah total pasangan data adalah jumlah kombinasi data TDS tersampel yaitu $\mathrm{C}(41,2)=820$. Untuk mencari nilai sill dan range yang akan digunakan harus melakukan analisis lanjutan. Analisis lanjutan adalah dengan mencari nilai semivariogram teoritis. Model semivariogram teoritis dalam penelitian ini adalah semivariogram model spherical, exponential dan gaussian. Nilai sill dan range yang didapat menggunakan software $R$, digunakan dalam persamaan dari masing-masing semivariogram teoritis.

Tabel 3 Nilai Semivariogram Teoritis TDS Berdasarkan Model

\begin{tabular}{rrrrr}
\hline Pasangan $(N(h))$ & $\operatorname{Jarak}(h)$ & Spherical & Exponential & Gaussian \\
\hline 87 & 1214,6010 & 900,6853 & 728,5967 & 600,0225 \\
227 & 2552,4620 & 900,6853 & 991,2909 & 668,6461 \\
237 & 4145,9130 & 900,6853 & 1079,1260 & 668,6749 \\
181 & 5781,6890 & 900,6853 & 1100,8930 & 668,6749 \\
68 & 7399,2370 & 900,6853 & 1106,0030 & 668,6749 \\
18 & 8998,3400 & 900,6853 & 1107,2220 & 668,6749 \\
2 & 10414,0170 & 900,6853 & 1107,5020 & 668,6749 \\
& MSE & 761488,7870 & 564009,0697 & 1063434,7190 \\
\hline
\end{tabular}

Kemudian analisis lanjutan dilakukan untuk melihat model semivariogram teoritis semivariogram teoritis yang terbaik menggunakan nilai Mean Square Error (MSE). Nilai MSE yang terbaik adalah nilai semivariogram teoritis dengan model exponential dengan nilai sill 1107,6144 dan range 1132,6210. Nilai sill dan range tersebut digunakan dalam proses estimasi TDS. Plot semivariogram TDS model exponential dapat dilihat dalam Gambar 2.

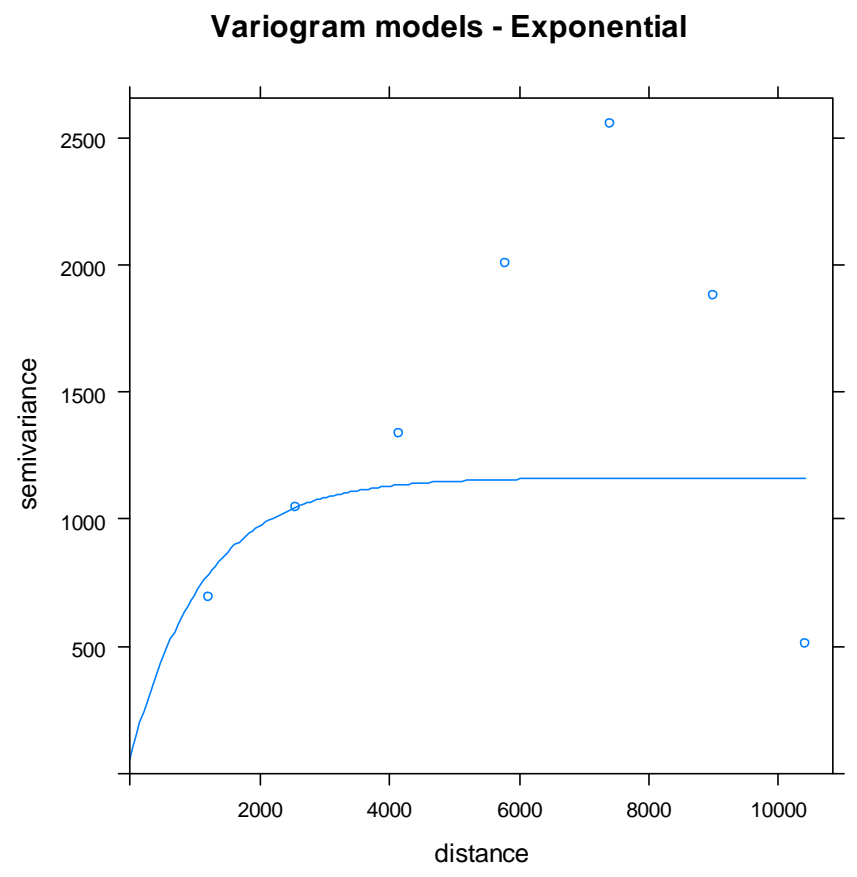

Gambar 2. Plot Semivariogram TDS Model Exponential

\section{Semivariogram Kesadahan $\left(\mathrm{CaCo}_{3}\right)$}

Dalam Tabel 4 disajikan nilai semivariogram eksperimental dari kesadahan yang dibantu dengan menggunakan software $R$. 
Tabel 4 Nilai Semivariogram Eksperimental Kesadahan

\begin{tabular}{rrrr}
\hline Kelas Jarak & Pasangan $(N(h))$ & Jarak $(h)$ & Semivariogram $(\gamma(h))$ \\
\hline $0-1667$ & 87 & 1214,6010 & 122,1264 \\
$1667-3334$ & 227 & 2552,4620 & 168,2731 \\
$3334-5001$ & 237 & 4145,9130 & 192,4135 \\
$5001-6668$ & 181 & 5781,6890 & 192,2431 \\
$6668-8335$ & 68 & 7399,2370 & 154,4559 \\
$8335-10002$ & 18 & 8998,3400 & 146,5556 \\
$10002-11669$ & 2 & 10414,0170 & 164,0000 \\
\hline
\end{tabular}

Jumlah total pasangan data adalah jumlah kombinasi data kesadahan tersampel yaitu $\mathrm{C}(41,2)=820$. Untuk mencari nilai sill dan range yang akan digunakan harus melakukan analisis lanjutan. Analisis lanjutan adalah dengan mencari nilai semivariogram teoritis. Model semivariogram teoritis dalam penelitian ini adalah semivariogram model spherical, exponential dan gaussian. Nilai sill dan range yang didapat menggunakan software $R$, digunakan dalam persamaan dari masing-masing semivariogram teoritis.

Tabel 5 Nilai Semivariogram Teoritis Kesadahan Berdasarkan Model

\begin{tabular}{rrrrr}
\hline Pasangan $(N(h))$ & $\operatorname{Jarak}(h)$ & Spherical & Exponential & Gaussian \\
\hline 87 & 1214,6010 & 52,5770 & 122,1223 & 49,3945 \\
227 & 2552,4620 & 98,7237 & 169,2853 & 131,1426 \\
237 & 4145,9130 & 119,8805 & 186,3254 & 163,3655 \\
181 & 5781,6890 & 120,0222 & 190,9364 & 166,0276 \\
68 & 7399,2370 & 120,0222 & 192,1199 & 166,0830 \\
18 & 8998,3400 & 120,0222 & 192,4283 & 166,0834 \\
2 & 10414,0170 & 120,0222 & 192,5054 & 166,0834 \\
& MSE & 3424,9837 & 625,0335 & 1245,7865 \\
\hline
\end{tabular}

Kemudian analisis lanjutan dilakukan untuk melihat model semivariogram teoritis yang terbaik menggunakan nilai Mean Square Error (MSE). Nilai MSE yang terbaik adalah nilai semivariogram teoritis dengan model exponential dengan nilai sill 192,5400 dan range 1207,5250. Nilai sill dan range tersebut digunakan dalam proses estimasi TDS. Plot semivariogram kesadahan model exponential dapat dilihat dalam Gambar 3.

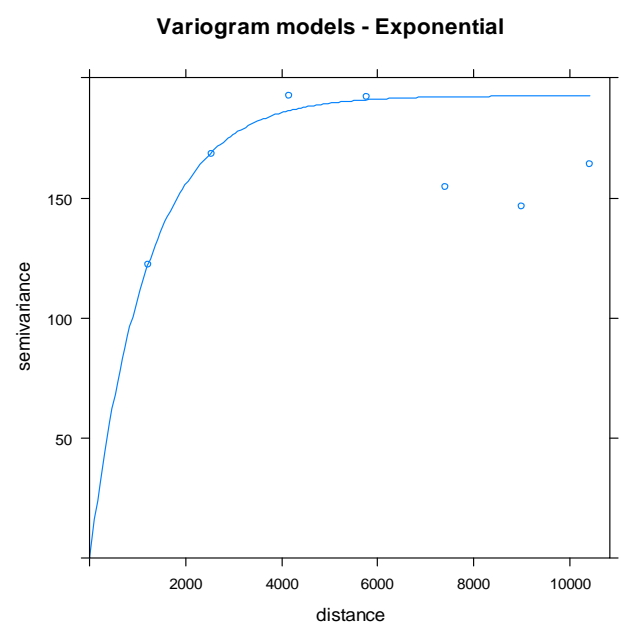

Gambar 3. Plot Semivariogram Kesadahan Model Exponential 


\section{Cross Semivariogram}

Dalam Tabel 6 disajikan nilai cross semivariogram eksperimental dari TDS dan kesadahan yang dibantu dengan menggunakan software $R$.

Tabel 6 Nilai Cross Semivariogram Eksperimental

\begin{tabular}{rrrc}
\hline Kelas Jarak & Pasangan $(N(h))$ & Jarak $(h)$ & Semivariogram $(\gamma(h))$ \\
\hline $0-1667$ & 174 & 1214,6010 & 231,5994 \\
$1667-3334$ & 454 & 2552,4620 & 285,4236 \\
$3334-5001$ & 474 & 4145,9130 & 321,9475 \\
$5001-6668$ & 362 & 5781,6890 & 410,4392 \\
$6668-8335$ & 136 & 7399,2370 & 463,9897 \\
$8335-10002$ & 36 & 8998,3400 & 341,8778 \\
$10002-11669$ & 4 & 10414,0170 & 285,8000 \\
\hline
\end{tabular}

Jumlah total pasangan data adalah jumlah permutasi data TDS dan kesadahan tersampel yaitu $\mathrm{P}(41,2)$ $=1640$. Untuk mencari nilai sill dan range yang akan digunakan harus melakukan analisis lanjutan. Analisis lanjutan adalah dengan mencari nilai cross semivariogram teoritis. Model cross semivariogram teoritis dalam penelitian ini adalah cross semivariogram model spherical, exponential dan gaussian. Nilai sill dan range yang didapat menggunakan software $R$, digunakan dalam persamaan dari masing-masing cross semivariogram teoritis.

Tabel 7 Nilai Cross Semivariogram Teoritis Berdasarkan Model

\begin{tabular}{rrrrr}
\hline Pasangan $(N(h))$ & Jarak $(h)$ & Spherical & Exponential & Gaussian \\
\hline 174 & 1214,6010 & 231,5995 & 223,0357 & 180,3868 \\
454 & 2552,4620 & 310,9036 & 306,4868 & 304,3509 \\
474 & 4145,9130 & 310,9036 & 335,5802 & 311,0980 \\
362 & 5781,6890 & 310,9036 & 343,1404 & 311,1108 \\
136 & 7399,2370 & 310,9036 & 345,0027 & 311,1108 \\
36 & 8998,3400 & 310,9036 & 345,4685 & 311,1108 \\
4 & 10414,0170 & 310,9036 & 345,5806 & 311,1108 \\
& MSE & 5100,4971 & 3282,3574 & 5417,7164 \\
\hline
\end{tabular}

Kemudian analisis lanjutan dilakukan untuk melihat model cross semivariogram teoritis yang terbaik menggunakan nilai MSE. Nilai MSE yang terbaik adalah nilai cross semivariogram teoritis dengan model exponential dengan nilai sill 345,6284 dan range 1171,8230. Nilai sill dan range tersebut digunakan dalam proses estimasi TDS. Plot cross semivariogram TDS dan kesadahan model exponential dapat dilihat dalam Gambar 4. 


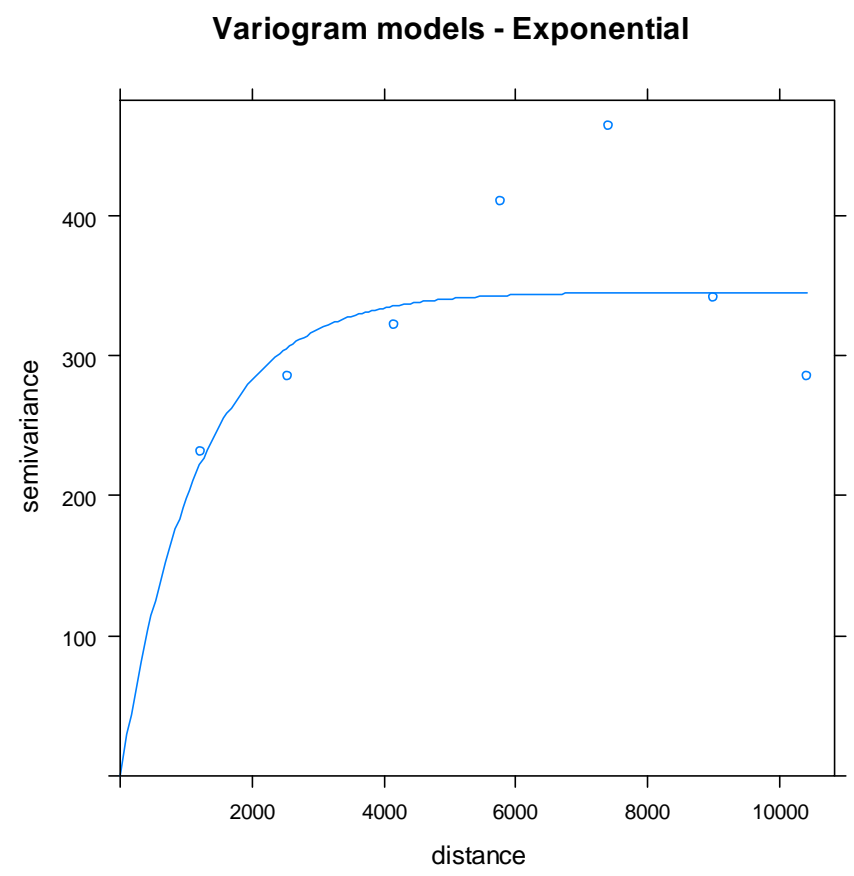

Gambar 4. Plot Cross Semivariogram TDS dan Kesadahan Model Exponential

\section{Hasil Estimasi Total Dissolved Solid}

Setelah memperoleh bentuk semivariogram teoritis yang paling baik untuk variabel utama, variabel tambahan dan cross semivariogramnya, maka nilai sill dan range dari semivariogram teoritis tersebut digunakan untuk mengestimasi TDS di sembilan titik lokasi baru yang telah ditentukan dengan melihat lokasi air yang masih digunakan masyarakat untuk keperluan higiene sanitasi. Sembilan titik lokasi tersebut dapat dilihat pada Gambar 5.
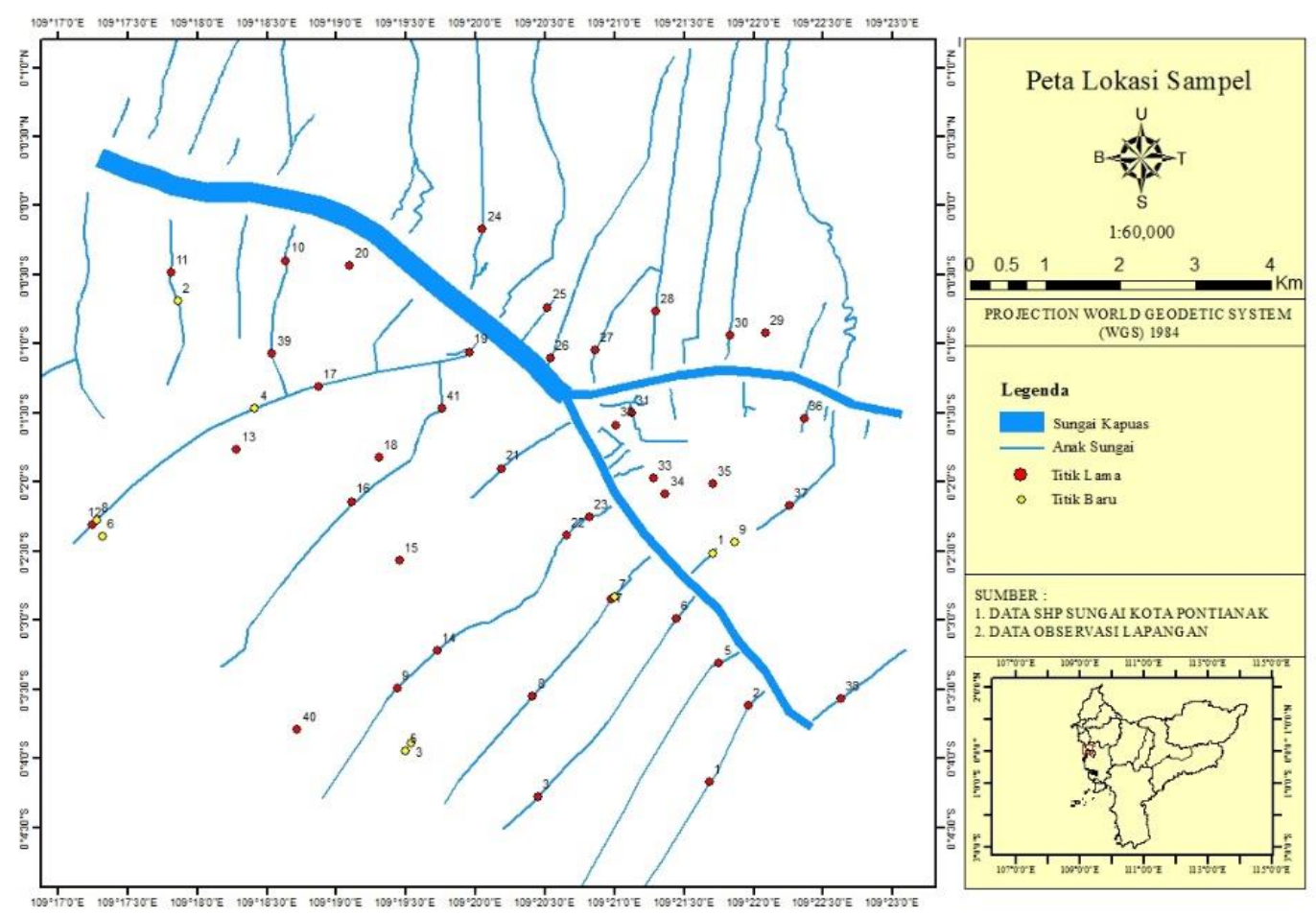

Gambar 5. Peta Lokasi Baru 
Nilai sill dan range yang digunakan dapat dilihat dalam Tabel 8.

Tabel 8 Nilai Sill dan Range Model Semivariogram yang Digunakan

\begin{tabular}{|l|l|l|l|}
\hline & Model & sill & range \\
\hline Semivariogram TDS & Exponential & 1107,6144 & 1132,6210 \\
\hline $\begin{array}{l}\text { Semivariogram } \\
\text { Kesadahan }\end{array}$ & Exponential & 192,5400 & 1207,5250 \\
\hline Cross Semivariogram & Exponential & 345,6247 & 1171,7940 \\
\hline
\end{tabular}

Digunakan software $\mathrm{R}$ untuk membantu dalam proses estimasi TDS. Hasil estimasinya dapat dilihat dalam Tabel 9.

Tabel 9 Nilai Estimasi Total Dissolved Solid di Lokasi yang Belum Tersampel

\begin{tabular}{lccr}
\hline \multicolumn{1}{c}{ Lokasi } & $x$ & $y$ & $\begin{array}{r}\text { Estimasi TDS } \\
(\mathrm{mg} / \mathrm{l})\end{array}$ \\
\hline Jl Moh Yusuf Karim & 317681,9204 & 9995371,1847 & 18,0 \\
Jl Karet & 310547,9534 & 9998737,5543 & 21,4 \\
Jl Parit Demang No 25 & 313665,1293 & 9992837,0304 & 17,6 \\
Jl Puskemas Pal 3 & 311577,7151 & 9997300,0380 & 26,9 \\
Parit Tokaya & 313581,6409 & 9992726,4500 & 76,3 \\
Jl Ampera & 309549,1655 & 9995598,3137 & 33,5 \\
Jl Tanjung Harapan & 316367,7264 & 9994787,5605 & 45,2 \\
Pal 5 & 309471,8523 & 9995807,1849 & 58,6 \\
Jl Tani & 317975,6802 & 9995521,6962 & 17,2 \\
\hline
\end{tabular}

Pada tabel 9 dapat dilihat bahwa nilai estimasi TDS terbesar berada di parit di Parit Tokaya yang mempunyai koordinat absis 313581,6409 dan ordinat 9992726,4500 dengan kadar TDS sebesar 76,3 mg/l. Nilai estimasi TDS terkecil berada di parit sekitar Jalan Tani dengan absis 317975,6802 dan ordinat 9995521,6962 dengan kadar TDS sebesar 17,2 mg/l.

\section{PENUTUP}

Berdasarkan hasil analisis dan pembahasan yang telah dilakukan, diperoleh model semivariogram yang digunakan untuk membantu mengestimasi TDS dalam penelitian ini. Semivariogram teoritis TDS yang digunakan adalah model exponential, semivariogram teoritis kesadahan yang digunakan adalah model exponential dan cross semivariogram antara TDS dan kesadahan yang digunakan adalah model exponential. Berdasarkan model semivariogram teoritis yang digunakan, diperoleh estimasi TDS di sembilan titik lokasi yang ditentukan dan airnya digunakan untuk kebutuhan higiene sanitasi masyarakat di sekitar lokasi tersebut. Hasil estimasi TDS terbesar di Parit Tokaya yaitu sebesar 76,3 $\mathrm{mg} / \mathrm{l}$ dan hasil estimasi terkecil di parit sekitar Jalan Tani yaitu sebesar 17,2 mg/l.

\section{DAFTAR PUSTAKA}

[1]. Wackernagel, H. Multivariate Geostatistics : An Introduction with Applications. Springer, New York; 1995

[2]. Armstrong, M. Basic Linear Geostatistics. Springer, Berlin; 1998

[3]. Isaaks, H,E, dan Srivastava, R. Applied Geostatistics. New York: Oxford University Press; 1989

[4]. Debataraja, N. N., Kusnandar, D., dan Nusantara, R. W. Identifikasi Lokasi Sebaran Pencemaran Air di Kawasan Permukiman Kota Pontianak. Jurnal Matematika, Statistika, dan Komputasi. 2018; 15(1); 37-41. 
MARWALIDA RACHMADIAR

DEBATARAJA

HENDRA PERDANA
: Jurusan Matematika FMIPA UNTAN, Pontianak

marwalidarachmadiar@student.untan.ac.id

NESSYANA : Jurusan Matematika FMIPA UNTAN,

Pontianak

naominessyana@math.untan.ac.id

: Jurusan Matematika FMIPA UNTAN,

Pontianak

hendra.perdana@math.untan.ac.id 